\title{
Leaf Rust on Aegilops speltoides Caused by a New Forma Specialis of Puccinia triticina
}

\author{
Pnina Ben Yehuda, Tamar Eilam, Jacob Manisterski, Ayelet Shimoni, and Yehoshua Anikster
}

First, third, and fifth authors: Institute for Cereal Crops Improvement, George S. Wise Faculty of Life Sciences, Tel Aviv University, Tel Aviv 69978, Israel; and second, fourth, and fifth authors: Department of Plant Sciences, George S. Wise Faculty of Life Sciences, Tel Aviv University, Tel Aviv 69978, Israel.

Accepted for publication 15 August 2003.

\begin{abstract}
Ben Yehuda, P., Eilam, T., Manisterski, J., Shimoni, A., and Anikster, Y. 2004. Leaf rust on Aegilops speltoides caused by a new forma specialis of Puccinia triticina. Phytopathology 94:94-101.

A leaf rust attacking Aegilops speltoides in its natural habitat is reported for the first time. It was found in two locations in northern and central Israel. The two collections from A. speltoides resemble wheat leaf rust, Puccinia triticina, in most spore dimensions, in the morphology of

lates taken from A. speltoides are compatible with Thalictrum speciosissimum as an aecial host and they are crossed easily with wheat leaf rust isolates. However, isolates from A. speltoides differ from wheat leaf rust in their telial host range. They are avirulent to cultivated wheat cultivars, but attack hundreds of $A$. speltoides accessions that were immune to wheat leaf rust. This distinct host preference justifies delineation of the newly found leaf rust as a forma specialis (f. sp. speltoides) within $P$. triticina.
\end{abstract} the substomatal vesicle of the urediniospore, and in DNA content in pycniospore nuclei. Similarly to $P$. triticina isolates from wheat, iso-
Additional keywords: basidiospores, teliospore germination.
Leaf rust caused by Puccinia triticina Eriks. \& E. Henn. is a major disease of cultivated wheat worldwide (23). The harmfulness of $P$. triticina, like that of other rust fungi, is connected with its wide distribution and long-distance dissemination, as well as with its ability to mutate, forming new races and attacking previously resistant cultivars (24). Wheat leaf rust is controlled largely by resistance genes in cultivated wheat (23). Important sources of additional resistance genes are the wild relatives of cultivated wheat (12).

The wild relatives of wheat can be grouped into primary, secondary, and tertiary gene pools (5). This classification reflects the ease of gene transfer to cultivated wheat. The secondary pool includes diploid species of Aegilops L., section Sitopsis, the putative donors of genome B in wheat (4). The most promising source of resistance genes in this group is the species Aegilops speltoides Tausch, as has been shown by many greenhouse and field nursery tests $(3,4,15,22)$. From this species, which has proved to be immune to the $P$. triticina form found on wheat cultivars, four genes for resistance to leaf rust, named $\operatorname{Lr} 28, \operatorname{Lr} 35, \operatorname{Lr} 36$, and $L r 47$, have already been transferred to cultivated wheat $(7,14,17)$.

In their work on leaf rust of wheat, rye, and Aegilops spp., Anikster et al. (2) pointed to the existence of two separate groups. The $P$. triticina group attacks wild and cultivated wheat, and its aecial host is Thalictrum speciosissimum L. (Ranunculaceae). The second group, the $P$. recondita Roberge ex Desmaz. complex, comprises different virulence types that are known to attack rye, durum wheat, and Aegilops spp., respectively. Different aecial hosts are known for this group, all of which are members of the family Boraginaceae. Hundreds of $A$. speltoides lines tested by us were immune to $P$. triticina and to all taxa within the $P$. recondita complex $(2,13)$.

Corresponding author: Y. Anikster; E-mail address: aniksty@post.tau.ac.il

Publication no. P-2003-1028-02R

(C) 2004 The American Phytopathological Society
This is the first report of leaf rust on A. speltoides in a natural habitat. The objective of this study was to identify this leaf rust pathogen, delimit it from the $P$. triticina form that attacks wheat, and assess the possible threat it may present to cultivated wheat.

\section{MATERIALS AND METHODS}

Rust collections and cultures. Collections and cultures of three leaf rusts used in this study (Table 1) were (i) the newly discovered rust associated with A. speltoides which is referred to as the speltoides type in this article; (ii) the wheat leaf rust fungus, $P$. triticina, referred to as the wheat type, and (iii) a $P$. recondita form, associated with A. longissima Schweinf. and Muschl., referred to as the longissima type. This form is avirulent to tetraploid wheats (3).

The speltoides type sample 9934 was collected by us on $A$. speltoides plants growing on stony terra rossa soil in a nonirrigated olive grove near Ahihud in Western Galilee, Israel, in June 1997. The green leaves of the host plant were densely covered with uredinia and telia. We collected samples 9977 and 99133 in 1998 and again in 2001 from the same host population in the same location. Collection 9981 (telia only) was gathered at Qazir on the slopes of the Samarian Mountains, Israel, in June 1998. Culture 3117 is an $S_{1}$ generation derived from 9981, a sample which was selfed on a $T$. speciosissimum host plant in the greenhouse at Tel Aviv University. (More collections of the speltoides type were made at Ahihud in 1999, 2000, and 2002, and at Qazir in 2002). Cultures of the speltoides type were increased on A. speltoides plants in the greenhouse.

In the wheat type group, the uredinial culture 1010 of $P$. triticina originated from Triticum turgidum subsp. dicoccoides Körn. ex Asch. and Graebn. Thell., in a field nursery at the Israel Agricultural Research Center at Bet Dagan near Tel Aviv in 1980. This culture is used widely in different studies at Tel Aviv University. Several additional collections of $P$. triticina were used for comparisons to the new speltoides type rust and for crossing experi- 
ments. Collection 2810 originated on a durum wheat in Ethiopia. The $S_{1}$ generation of this collection, 77059, was used for crossing experiments. Collection 9972, found on bread wheat in a field nursery in the Bet-Shean Valley in Northern Israel, also was used for crossing experiments, as representing a rust parasitic on hexaploid wheat.

The longissima type of $P$. recondita is represented in this study by collection 9962, derived from an A. longissima plant at Bet Gamliel in Central Israel. We used this collection for comparisons of host ranges and comparisons of morphological traits. Samples of the indicated fungal isolates have been deposited in the Arthur Herbarium, West Lafayette, IN (Table 1).

Host range studies, uredinial stage. Pathogenicity of the speltoides type, compared with the wheat and longissima types, was tested on a wide range of Aegilops and Triticum genotypes. The bread and durum wheat cultivars tested were of worldwide origin, mostly with a known susceptibility to wheat leaf rust (Table 2).

Seedlings (5 to 10) of each line were grown in $10-\mathrm{cm}$-diameter plastic pots in an air conditioned greenhouse at $21 \pm 2{ }^{\circ} \mathrm{C}$. Inoculation at the first- to second-leaf stage was performed by spraying the seedlings with a suspension of urediniospores in light mineral oil (Soltrol 170). The oil was allowed to evaporate for $30 \mathrm{~min}$, and the inoculated seedlings were placed in a dew chamber at $18^{\circ} \mathrm{C}$ for $24 \mathrm{~h}$, after which they were returned to the greenhouse at $21 \pm$ $2{ }^{\circ} \mathrm{C}$. Host reactions were recorded at 10 to 14 days after inoculation, according to a 0 -to-3 scale from immune to highly susceptible, with $0=$ no visible reaction, $0 ;=$ small chlorotic flecks, $1=$ small uredinia with minimal sporulation and chlorosis, $2=$ moderately small uredinia with chlorosis, and $3=$ large uredinia, sometimes with chlorosis.
Teliospore germination and inoculation of the aecial hosts. Teliospores were induced to germinate by the method of Anikster (1). Leaf pieces bearing telia were floated on water in petri dishes at 5 to $6^{\circ} \mathrm{C}$ for 2 to 10 weeks, then shifted to $20^{\circ} \mathrm{C}$ for germination. Promycelia and basidiospores were observed microscopically to check for teliospore germination. Transparent cylinders, made of 0.3 -mm-thick polyvinylchloride, were placed over single candidate aecial host plants in 20 -cm-diameter plastic pots. The open top of each cylinder was covered with wet filter paper bearing the excised leaf squares with germinating teliospores on its underside, so that basidiospores could fall on the plant beneath. The pots with their enclosures of germinating teliospores were placed in a high humidity chamber and incubated at $21 \pm 2^{\circ} \mathrm{C}$ for $48 \mathrm{~h}$. After removal of the filter paper, the pots with open cylinders still in place were moved to an insect-proof greenhouse at $21 \pm 2{ }^{\circ} \mathrm{C}$. Pycnia appeared 8 to 12 days after inoculation.

Host range studies, pycnial and aecial stage. In the search for an aecial host of the speltoides type rust, a group of candidate species was assembled for tests of pycnial and aecial stages of the fungus. This group, the aecial test set, included (i) Ranunculaceae: Thalictrum speciosissimum, which is known as the aecial host for P. triticina but does not grow wild in Israel, and Ranunculus arvensis L., which does grow in the vicinity of the Ahihud area, where the speltoides type rust was found; (ii) Boraginaceae: Anchusa aggregata Lehm., which serves as an aecial host for $P$. recondita, the leaf rust that attacks all members of Aegilops section Sitopsis, except Aegilops speltoides; Anchusa italica Retz, the aecial host of the $P$. recondita that attacks durum wheat in Morocco, Portugal, and Spain; Lycopsis arvensis L., the aecial host of the $P$. recondita that attacks rye; and Echium glomeratum

TABLE 1. Telial and uredinial collections and cultures of Puccinia triticina f. sp. speltoides (speltoides type), $P$. triticina f. sp. tritici (wheat type), and $P$. recondita (longissima type) used in this study

\begin{tabular}{|c|c|c|c|c|c|}
\hline Rust species & $\begin{array}{l}\text { Collection } \\
\text { no. }{ }^{y}\end{array}$ & Host species & Origin & $\begin{array}{l}\text { Year of } \\
\text { collection }\end{array}$ & Voucher no. ${ }^{\mathrm{z}}$ \\
\hline Speltoides type & $9934 \mathrm{u}$ & Aegilops speltoides & Ahihud, Northern Israel & 1997 & PUR N 4487 \\
\hline Speltoides type & $9934 \mathrm{t}$ & A. speltoides & Ahihud, Northern Israel & 1997 & PUR N 4486 \\
\hline Speltoides type & $9977 \mathrm{t}$ & A. speltoides & Ahihud, Northern Israel & 1998 & PUR N 4488 \\
\hline Speltoides type & $99133 \mathrm{t}$ & A. speltoides & Ahihud, Northern Israel & 2001 & PUR N 4489 \\
\hline Speltoides type & $9981 \mathrm{t}$ & A. speltoides & Qazir, Samarian Mountains, Israel & 1998 & PUR N 4485 \\
\hline Speltoides type & $3117 \mathrm{u}$ & A. speltoides & $\mathrm{S}_{1}$ generation of 9981 , produced in Tel Aviv & 1999 & $\ldots$ \\
\hline Wheat type & $1010 \mathrm{u}$ & Triticum turgidum subsp. dicoccoides & Bet Dagan field nursery & 1980 & PUR N 4480 \\
\hline Wheat type & $77059 \mathrm{t}$ & T. turgidum subsp. durum & $\begin{array}{l}\mathrm{S}_{1} \text { generation of Ethiopian isolate } 2810 \text {, } \\
\text { produced in Tel Aviv }\end{array}$ & 1998 & PUR N 4478 \\
\hline Wheat type & $9972 \mathrm{t}$ & T. aestivum & Bet Shean, Northern Israel & 1998 & PUR N 4482 \\
\hline Longissima type & $9962 \mathrm{t}$ & A. longissima & Bet Gamliel, Central Israel & 1998 & PUR N 4483 \\
\hline Longissima type & $9962 \mathrm{u}$ & A. longissima & $\mathrm{S}_{1}$ generation of $9962 \mathrm{t}$, produced in Tel Aviv & 1998 & $\ldots$ \\
\hline
\end{tabular}

y $\mathrm{u}=$ uredinial stage and $\mathrm{t}=$ telial stage.

${ }^{\mathrm{z}}$ Herbarium specimen number in the Arthur \& Kriebel Herbaria, West Lafayette, IN.

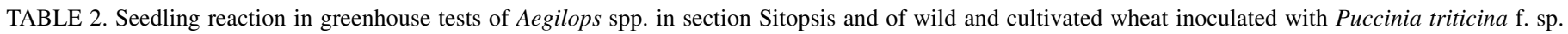
speltoides (speltoides type), $P$. triticina f. sp. tritici (wheat type), and $P$. recondita (longissima type)

\begin{tabular}{|c|c|c|c|c|c|c|c|}
\hline \multirow[b]{2}{*}{ Host species (genome symbol) } & \multicolumn{3}{|c|}{ Host } & \multicolumn{4}{|c|}{ Reaction $^{\mathrm{w}}$} \\
\hline & Origin & No. of locations & No. of lines & $9934 \mathrm{u}$ & $3117 \mathrm{u}$ & $1010 \mathrm{u}$ & $9962 \mathrm{u}$ \\
\hline Aegilops speltoides (S) & Middle East & 16 & 300 & 3 & 3 & 0,0 & 0,0 \\
\hline A. bicornis $\left(\mathrm{S}^{\mathrm{b}}\right)$ & Israel & 4 & 13 & 3 & 3 & 3 & 3 \\
\hline A. longissima $\left(\mathrm{S}^{\mathrm{l}}\right)$ & Israel & 6 & 28 & 3 & 3 & 3 & 3 \\
\hline A. searsii $\left(\mathrm{S}^{\mathrm{s}}\right)$ & Israel & 3 & 13 & 3 & 3 & 3 & 3 \\
\hline A. sharonensis $\left(\mathrm{S}^{\mathrm{sh}}\right)$ & Israel & 5 & 22 & 3 & 3 & $0 ;, 1,3^{\mathrm{x}}$ & $1,3^{\mathrm{x}}$ \\
\hline Triticum turgidum subsp. dicoccoides (AB) & Israel & 30 & 103 & $0 ;, 1,3^{\mathrm{x}}$ & $0 ;, 1,3^{\mathrm{x}}$ & 3 & 0,0 \\
\hline T. turgidum subsp. dicoccum $(\mathrm{AB})^{\mathrm{y}}$ & Worldwide & $\ldots$ & 5 & 0,0 & 0 & 3 & 0 \\
\hline T. turgidum subsp. durum $(\mathrm{AB})^{\mathrm{z}}$ & Worldwide & $\ldots$ & 70 & 0 & 0,0 & 3 & 0,0 \\
\hline T. aestivum $(\mathrm{ABD})^{\mathrm{z}}$ & Worldwide & $\ldots$ & 40 & 0,0 & 0,0 & 3 & 0,0 \\
\hline
\end{tabular}

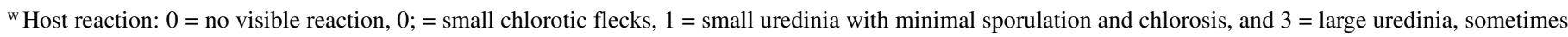
with chlorosis. Speltoides type, $9934 \mathrm{u}$ and $3117 \mathrm{u}$; wheat type, $1010 \mathrm{u}$; and longissima type, $9962 \mathrm{u}$.

$x$ Variable reaction between host species lines.

y Different cultivars received from M. Feldman, The Weizmann Institute of Sciences, Rehovot, Israel.

${ }^{\mathrm{z}}$ Different cultivars received from A. P. Roelfs, University of Minnesota, St. Paul. 
Poir., which is the aecial host for the local native $P$. recondita that attacks Aegilops ovata. Each member of this group was inoculated with the speltoides type rust in at least 10 replicates growing in separate pots. Inoculations of the different candidate host species were performed at the same time, and the same speltoides type cultures were used for all. For comparison, we also inoculated the aecial test set with collections of the wheat and longissima types of leaf rust.

Selfing of individual collections and crossing experiments. Collections of both the speltoides and the wheat types of leaf rust were self-fertilized on $T$. speciosissimum hosts as follows: 2 to 5 days after appearance of pycnial clusters, nectar was transferred from one pycnial cluster of a given isolate to another cluster of the same isolate and vice versa, using either a no. 0 artist's brush that had been moistened with water, or a thin-walled capillary tube. Each pair of clusters was marked. Aecia appeared 7 to 10 days after these transfers.

The same speltoides type and wheat type collections that were selfed also were intercrossed on the aecial host. These speltoides type $\times$ wheat type crosses were performed by transferring nectar from a single pycnial cluster of one type to a single pycnial cluster of the second type. Pycnial clusters used as recipients had to be at least $1 \mathrm{~cm}$ apart from each other and more than 10 days old, so that aecia resulting from any uncontrolled fertilization were visible and could be discarded. The same procedure was used for crossing experiments of the speltoides type with the longissima type rust.

Each single aecial cluster resulting from a self fertilization or cross was marked as a separate culture. For inoculations of the telial hosts of both parental cultures, aeciospores were vacuumed into gelatin capsules and suspended in Soltrol 170 prior to inoculation. The telial hosts were two A. speltoides accessions, 308 and 818; Triticum aestivum cv. Thatcher; and T. turgidum subsp. durum cv. Local Red.

Spore morphology. Teliospores were scraped from dry leaves of A. speltoides, A. longissima, and T. aestivum. The teliospores were mounted in $50 \%$ glycerol on glass slides. Our longstanding experience in measuring teliospores in this mount has shown that their dimensions are not affected by the environment. Video images were taken with a Zeiss Axioskop microscope (Germany), using a $\times 20$ objective and $\times 10$ ocular lenses. The images were obtained with a CCD B/W video camera (LIS-700 Applitec, Israel). We digitized and analyzed the images, using image-analysis
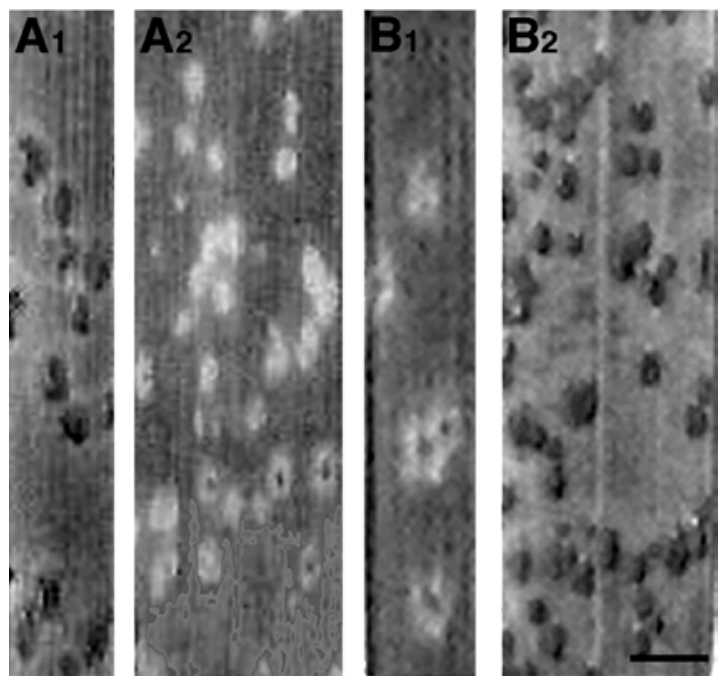

Fig. 1. Reactions of Aegilops speltoides and Triticum turgidum subsp. durum cv. Local Red to the Puccinia triticina f. sp. speltoides (speltoides type) and P. triticina f. sp. tritici (wheat type) 14 days after inoculation. $\mathbf{A}_{\mathbf{1}}$, Speltoides type on A. speltoides; $\mathbf{A}_{2}$, speltoides type on cv. Local Red; $\mathbf{B}_{1}$, wheat type on A. speltoides; and $\mathbf{B}_{2}$, wheat type on cv. Local Red. Bar $=3 \mathrm{~mm}$. software (NIH Image, 1.62). The length of spores, excluding their pedicel, and their width at the widest part of the spore were measured. The areas within their outline boundaries, excluding the pedicel, were determined in numbers of pixels and calibrated to dimensional units. At least 50 teliospores were measured per collection.

Basidiospores were collected by placing glass slides under leaf segments bearing telia of leaf rust samples, all of which had been pretreated to induce teliospore germination. The basidiospores were mounted in lactophenol cotton blue and slightly heated for 5 min. Their cross-sectional areas then were measured as described for teliospores.

Urediniospores of the three rusts were collected in the greenhouse from uredinia on plants of $A$. speltoides, A. longissima, and T. aestivum. Aeciospores were collected from aecia that developed on greenhouse-grown Thalictrum speciosissimum and Anchusa aggregata that had been inoculated with either of the three rust types. Urediniospores and aeciospores were mounted in 50\% glycerol, and their cross-sectional areas were measured as described previously.

Germ pores were counted in urediniospores by the squash technique of Jennings et al. (11). The spores were stained in aniline blue and then heated until "smoke" emerged from the slide. A coverslip was placed over the spores and pressed hard against them. A Zeiss Axioskop microscope was used to accentuate the germ pores. Germ pores were counted in at least 50 urediniospores in each collection. Means, standard deviations, and coefficients of variations for all spore measurements were calculated using the computer program Microsoft Excel. Differences among means were evaluated by multiple comparisons using the Tukey's test $(P=0.05)$.

Substomatal vesicles. Seedling leaves of barley cv. L-94 were inoculated with urediniospores for production of substomatal vesicles of the three rusts. This barley cultivar is widely used as a "nonhost" for the comparisons of substomatal vesicle morphology of different rust fungi (19). In each case, a concentrated spore suspension was applied to the first seedling leaf with a cotton swab. Inoculated seedlings were incubated in a dew chamber for $24 \mathrm{~h}$, and substomatal vesicles were examined in leaf mounts, following the procedure of Niks (18) and Niks and Dekens (19), with two modifications. Leaf segments were boiled in $0.03 \%$ (rather than in $0.005 \%)$ trypan blue in lactophenol-ethanol $(1: 2$, $\mathrm{vol} / \mathrm{vol}$ ) for $30 \mathrm{~s}$ at a low intensity in a microwave oven (instead of being boiled for $15 \mathrm{~min}$ ). Leaf segments then were cleared with aqueous chloral hydrate $(5: 2, \mathrm{wt} / \mathrm{vol})$ and mounted in glycerol for viewing with a Zeiss microscope $(\times 630)$, using DIC optics.
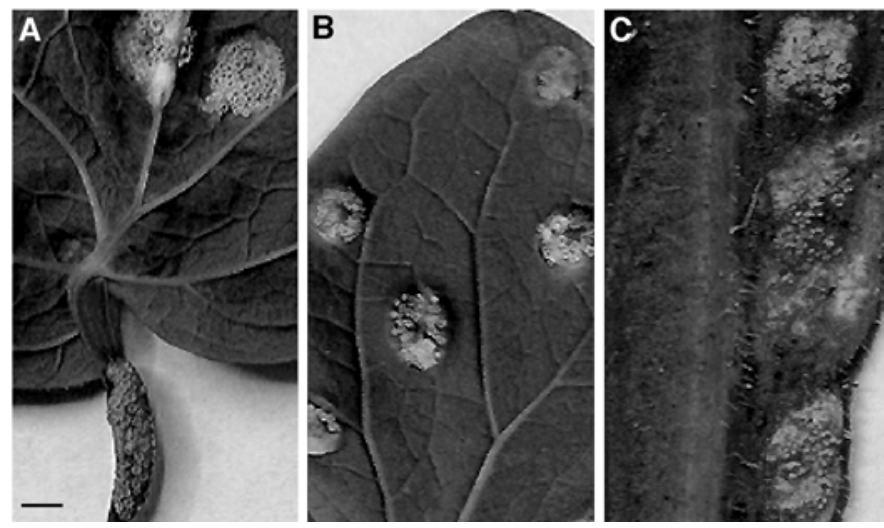

Fig. 2. Aecial cultures of Puccinia triticina f. sp. speltoides (speltoides type), $P$. triticina $\mathrm{f}$. sp. tritici (wheat type), and $P$. recondita (longissima type) on their aecial hosts 22 days after inoculation. A, Speltoides type on Thalictrum speciosissimum, abaxial leaf surface; B, wheat type on T. speciosissimum, adaxial leaf surface; and $\mathbf{C}$, longissima type on Anchusa aggregata, abaxial leaf surface. Bar $=1 \mathrm{~mm}$. 
Images were taken with a Nikon Coolpix 990 digital camera. At least 50 substomatal vesicles were examined in each rust type.

DNA content of pycniospore nuclei. The relative DNA content of pycniospore nuclei was determined by flow cytometry of propidium iodide-stained spores, as described by Eilam et al. (8). Pycniospores were harvested 10 to 20 days after inoculation from T. speciosissimum plants inoculated with basidiospores of the speltoides and wheat types of leaf rusts and from A. aggregata plants inoculated with the longissima type. The buffer-dye solution of Tris- $\mathrm{HCl}$ buffer $(0.18 \mathrm{M}, \mathrm{pH} 7.2)$, containing propidium iodide at $4 \mu \mathrm{g} / \mathrm{ml}$, RNase at $50 \mu \mathrm{g} / \mathrm{ml}$, and Triton X-100 at $4 \mu \mathrm{g} / \mathrm{ml}$ (all chemicals from Sigma-Aldrich, St. Louis), was drawn into a glass hematocrit capillary tube (1-mm inside diameter). The tip of the tube was brought into contact with a pycnial cluster to allow pycnial nectar and pycniospores to enter the tube. Spores that had been collected from pycnial clusters were blown from the tube into $200 \mu \mathrm{l}$ of buffer-dye solution in a test tube. Pycniospores were allowed to stain for 2 to $3 \mathrm{~h}$ before being introduced into the flow cytometer. If stained spores could not be used immediately, they were stored at $-20^{\circ} \mathrm{C}$.

A Becton Dickinson (Mountain View, CA) FACS IV flow cytometer equipped with an argon laser was used to measure fluorescence intensity of stained pycniospores. Fluorescent intensity was expressed as channel number. The flow cytometer was calibrated daily with chicken red blood cells as a standard, bringing the output with $650 \mathrm{~mW}$ to channel number 100. Excitation was at $488 \mathrm{~nm}$; a $570-\mathrm{nm}$ emission filter was used. Pycniospores of $P$. hordei, harvested and processed in parallel with each spore sample, were used as a standard for comparison of relative DNA content, with the output of the flow cytometer set at channel number 100 for $P$. hordei pycniospores. The fluorescence of 10,400 pycniospores was measured in each cytometer run, and at least three runs were performed for each collection. Data were analyzed, using Win MDI version 2.8, a flow cytometer data analysis software by Joseph Trotter.

\section{RESULTS}

Telial hosts. The two collections of the speltoides rust used here, the one originating at Ahihud (9934 u [uredinial stage]) and the $S_{1}$ generation of 9981 from Qazir $(3117 \mathrm{u}$ ), were identical in the reaction they elicited (Table 2). All 300 Aegilops speltoides accessions tested, 296 from Israel, 2 from Turkey, and 2 from Syria, were compatible with the two speltoides type fungal cultures, showing a type 3 reaction (Fig. $1 \mathrm{~A}_{1}$ ). All accessions of $A$. bicornis, A. longissima, A. searsii, and A. sharonensis also were susceptible to these two rust isolates. On the other hand, all cultivated wheat, hexaploid bread wheat, as well as the tetraploid dicoccum and durum wheat, exhibited 0 or 0 ; reactions to the speltoides type (Table 2, Fig. $1 \mathrm{~A}_{2}$ ). Accessions of Triticum turgi- dum subsp. dicoccoides varied in their response to inoculations with speltoides type cultures: 58 accessions exhibited a type 3 reaction, while the other 45 accessions exhibited 0 or 0 ; reactions.

Not one of the 300 A. speltoides accessions was susceptible to inoculation with either the $P$. triticina wheat type isolate 1010 (Fig. $1 \mathrm{~B}_{1}$ ) or the longissima type, whereas all accessions of three other Aegilops spp. of section Sitopsis were susceptible to these two cultures, and only accessions of $A$. sharonensis varied in their response. All wheat lines, 115 cultivars and 103 accessions of wild $T$. dicoccoides, that were inoculated with the wheat type isolate, exhibited a type 3 reaction, but showed 0 or 0 ; reactions to the longissima type rust.

Aecial hosts. The results of inoculations of an aecial test set of candidate aecial hosts under controlled conditions with collections of the three leaf rust types showed clearly that Thalictrum speciosissimum can serve as aecial host of the speltoides type rust. In inoculation tests, the teliospores of all three speltoides type collections (9934, 9977, and 9981) and collections made in 1999, 2000, and 2002 were easily induced to germinate and resulted in hundreds of pycnial clusters on all $26 \mathrm{~T}$. speciosissimum plants tested (Fig. 2A). None of the other members of the aecial test set used by us were susceptible to the speltoides type isolates. As expected, the two wheat type isolates also infected the T. speciosissimum plants (Fig. 2B). The longissima type formed pycnial clusters on Anchusa aggregata plants only (Fig. 2C).

Selfing and crossing experiments. Self fertilizations within pycnial clusters of the two speltoides type isolates on $T$. speciosissimum host plants resulted in a total of 44 cultures. Aegilops speltoides accessions 308 and 818 exhibited type 3 reactions to inoculations with these cultures, whereas durum wheat cv. Local Red and bread wheat cv. Thatcher, both of which are susceptible to wheat leaf rust, gave reactions of 0 and 0 ; (Table 3 ). In parallel, self progenies of two wheat type isolates were produced: collection 77059 originating from durum wheat in Ethiopia and 9972 of bread wheat origin. The $A$. speltoides accessions responded with 0 and 0 ; reactions to inoculations with all selfed cultures, whereas the durum wheat cv. Local Red gave a 3 reaction to the same inoculations. Bread wheat $\mathrm{cv}$. Thatcher exhibited 0 and 0 ; reactions when inoculated with progenies of the isolate from durum wheat but type 3 reactions when inoculated with the selfed cultures of bread wheat origin.

All $33 \mathrm{~F}_{1}$ progenies from crosses between the speltoides and wheat types (Table 3 ) gave rise to a type 3 reaction on the two $A$. speltoides accessions and on the durum wheat cultivar, whereas the reactions on bread wheat Thatcher were 0 ; and 1 . All attempts to cross speltoides type with longissima type failed; no aecial clusters developed.

Studies of spore morphology. Dimensions of the four kinds of spores (teliospores, basidiospores, aeciospores, and uredinio-

TABLE 3. Host reactions to rust progenies derived from self fertilization of pycnial clusters on Thalictrum speciosissimum, and from cross fertilization between Puccinia triticina f. sp. speltoides (speltoides type) and P. triticina f. sp. tritici (wheat type)

\begin{tabular}{|c|c|c|c|c|c|c|c|}
\hline \multirow[b]{3}{*}{ Rust type } & \multirow[b]{3}{*}{ Collection no. } & \multirow[b]{3}{*}{ Type of culture } & \multirow[b]{3}{*}{ No. of cultures } & \multicolumn{4}{|c|}{ Reaction $^{x}$} \\
\hline & & & & \multicolumn{2}{|c|}{ A. speltoides } & \multicolumn{2}{|c|}{ Wheat ${ }^{y}$} \\
\hline & & & & 308 & 818 & Local Red & Thatcher \\
\hline Speltoides type & 9934 & Selfed & 24 & 3 & 3 & $0,1-$ & 0 \\
\hline Speltoides type & 9981 & Selfed & 20 & 3 & 3 & $0,1-$ & 0 \\
\hline Wheat type & 77059 & Selfed & 15 & 0 & 0 & 3 & 0 \\
\hline Wheat type & 9972 & Selfed & 14 & 0 & 0 & 3 & 3 \\
\hline Speltoides type/wheat type ${ }^{z}$ & $9934 / 77059^{z}$ & $\mathrm{~F}_{1}$ & 13 & 3 & 3 & $3,3+$ & 0 \\
\hline Wheat type/speltoides type ${ }^{z}$ & $77059 / 9934^{z}$ & $\mathrm{~F}_{1}$ & 8 & 3 & 3 & 3 & 0 \\
\hline Wheat type/speltoides type ${ }^{z}$ & $9972 / 9981^{z}$ & $\mathrm{~F}_{1}$ & 12 & 3 & 3 & 3 & $0 ;, 1$ \\
\hline
\end{tabular}

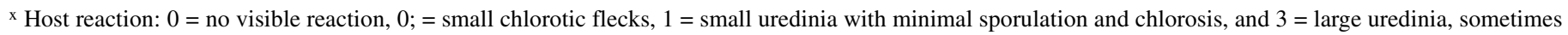
with chlorosis.

y Local Red - durum wheat cultivar, Thatcher - bread wheat cultivar.

z Nectar donor/nectar recipient. 
spores) were measured and compared in both collections of the speltoides type and in the wheat and longissima types (Table 4). Most spore dimensions did not differ between the speltoides type collections and the wheat type (Fig. 3). The only significant difference in spore dimensions between the two types of rust was the area of aeciospores, which was slightly larger in the speltoides type from Ahihud. The dimensions of all four kinds of spores of the longissima type were significantly larger than those of the speltoides and wheat types (Fig. 3C and $\mathrm{C}_{1}$ ).

Urediniospores of the wheat and the longissima types averaged one more germ pore than urediniospores of the speltoides type (Table 4).

The substomatal vesicle. The morphology of the substomatal vesicle (SSV) of the speltoides type urediniospores was similar to that of the wheat type (Fig. 4A and B), but these were different from the longissima type (Fig. 4C). The SSV in the wheat type was ovoid and aseptate and developed a single winding primary infection hypha on one side only, as described by Niks (18). The longissima type SSV was oblong and longer than the stoma with which it was aligned. A septum divided it into two parts of unequal length, and it developed primary infection hyphae at each end.
DNA content of pycniospore nuclei. Nuclei of pycniospores of the speltoides type contained amounts of DNA similar to those in the wheat type but significantly less DNA than nuclei of pycniospores in the longissima type (Fig. 5).

\section{DISCUSSION}

Distribution. We found the speltoides type of $P$. triticina at both the Ahihud and Qazir sites in each successive year since its discovery in 1997. During the same time, all our efforts to find this rust in any other populations of A. speltoides failed. Despite a thorough search for ranunculaceous species serving as aecial host of the speltoides type in the close vicinity of the Ahihud and Qazir A. speltoides populations, we found none. We conclude that urediniospores may remain alive on leaves and spikes of the dried plants during the hot and dry summer and serve as the primary inoculum for epidemics in each subsequent growing season. So far, this rust has been found in nature only in these two small populations in the very south of the distribution area of its telial host. On the other hand, in artificial inoculations under greenhouse conditions, the Ahihud and Qazir leaf rust collections were compatible with all accessions of Aegilops section Sitopsis tested

TABLE 4. Morphological traits of two Puccinia triticina f. sp. speltoides (speltoides type) cultures compared with cultures of $P$. triticina f. sp. tritici (wheat type) and $P$. recondita (longissima type)

\begin{tabular}{|c|c|c|c|c|}
\hline \multirow[b]{2}{*}{ Characters } & \multicolumn{2}{|c|}{ Speltoides type } & \multirow[b]{2}{*}{ Wheat type } & \multirow[b]{2}{*}{ Longissima type } \\
\hline & Ahihud & Qazir & & \\
\hline \multicolumn{5}{|l|}{ Teliospores } \\
\hline Length $(\mu \mathrm{m})$ & $46 \pm 5 \mathrm{a}(100)^{\mathrm{z}}$ & $45 \pm 6$ a (100) & $46 \pm 8$ a (261) & $49 \pm 6$ b (255) \\
\hline Area $\left(\mu \mathrm{m}^{2}\right)$ & $601 \pm 77$ a (100) & $576 \pm 76$ a (100) & $583 \pm 85$ a (261) & $773 \pm 100 \mathrm{~b}(255)$ \\
\hline \multicolumn{5}{|l|}{ Basidiospores } \\
\hline Area $\left(\mu m^{2}\right)$ & $36 \pm 6$ a (130) & $37 \pm 6 a b(242)$ & $39 \pm 7$ b (579) & $70 \pm 11 \mathrm{c}(538)$ \\
\hline Length $(\mu \mathrm{m})$ & $21 \pm 1$ a (131) & $22 \pm 1$ a (106) & $22 \pm 2$ a (303) & $26 \pm 1 b(163)$ \\
\hline Width $(\mu \mathrm{m})$ & $20 \pm 1 \mathrm{a}(131)$ & $19 \pm 1 \mathrm{a}(106)$ & $20 \pm 2 \mathrm{a}(303)$ & $24 \pm 2 b(163)$ \\
\hline Area $\left(\mu \mathrm{m}^{2}\right)$ & $350 \pm 34$ a (131) & $343 \pm 22$ a (106) & $360 \pm 54$ a (303) & $488 \pm 55 \mathrm{~b}(163)$ \\
\hline Number of germ pores & $7 \pm 1$ a (55) & $7 \pm 1$ a (53) & $8 \pm 1 \mathrm{~b}(47)$ & $8 \pm 1 \mathrm{~b}(62)$ \\
\hline Range & $5-9$ & $5-9$ & $7-11$ & $6-10$ \\
\hline
\end{tabular}

${ }^{\mathrm{z}}$ Mean \pm SD values within rows followed by different letters are statistically different $(P \leq 0.05)$ by Tukey's test. Numbers of spores examined are given in parentheses; $\mathrm{NA}=$ not available.
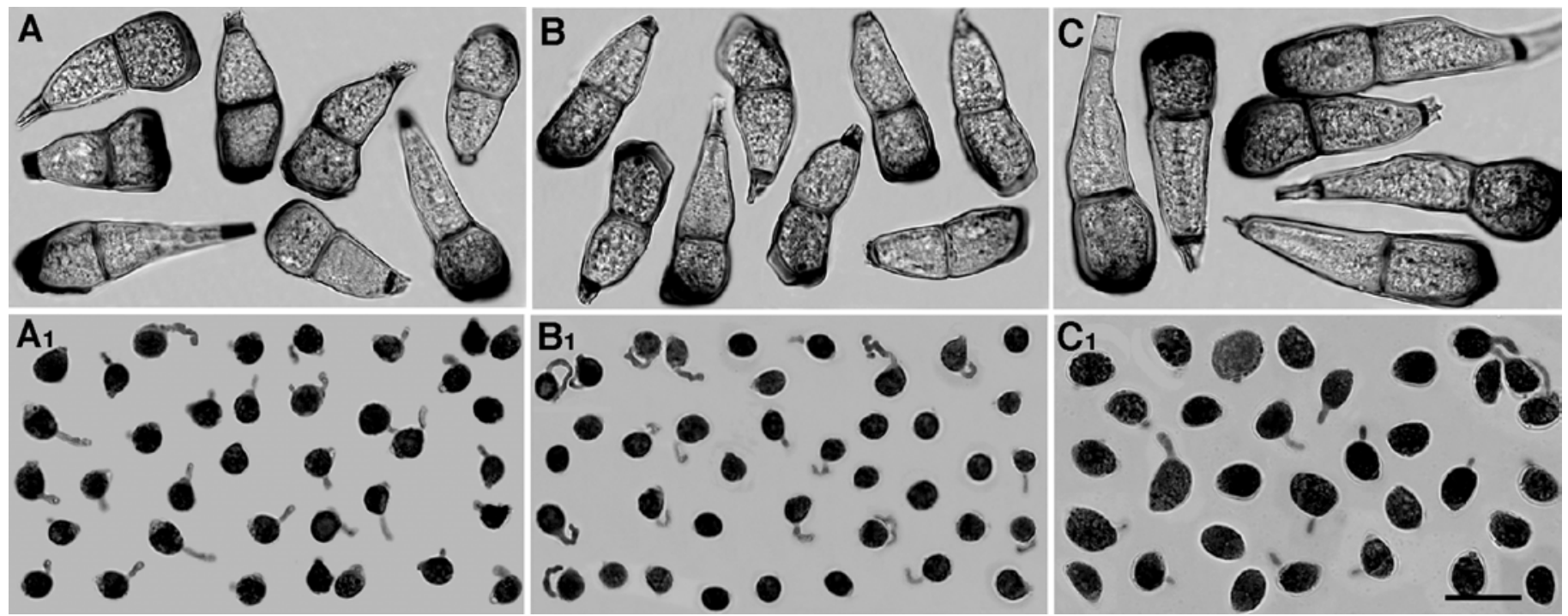

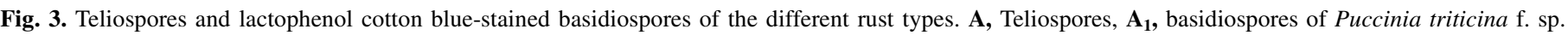

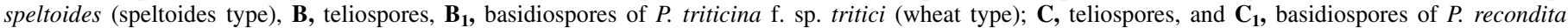
(longissima type). Bar $=15 \mu \mathrm{m}$. 
(Table 2). Compatibility with a wider host range under laboratory rather than natural conditions is a phenomenon that we have observed repeatedly in isolates of $P$. triticina, $P$. recondita, and other rust fungi $(21,25)$.

In Oeiras, Portugal, Freitas (10) found a leaf rust on A. speltoides (an alien species there) grown in a field nursery close to an aecia-bearing population of $T$. speciosissimum. This rust certainly belongs to the wheat type, because the author was successful in transferring it to wheat and identified it to be a common wheat leaf rust race.

Similarities between the speltoides and wheat types and differences between this group and the longissima type. The findings presented in this article confirm and expand the main results of our previous work (2). We conclude that there are two complexes of species, varieties, and forms of leaf rusts of Triticum, Secale, and related genera, such as Aegilops, Agropyron, and others. One group alternates on members of Ranunculaceae, mainly on the genus Thalictrum, and constitutes the P. triticina complex, also named $P$. persistens Plowr. by some European researchers (16). The second group alternates on members of Boraginaceae and the present authors designate it the $P$. recondita complex. Our conclusion differs from that of Cummins (6) and Wilson and Henderson (26), who combine all leaf rusts of wheat, rye, wheat relatives, and numerous other grass species rusts and assign them to $P$. recondita.

We used several independent, novel approaches to delineate differences between these two groups and also establish the position of the speltoides type rust.

The method for inducing teliospore germination under controlled conditions allows tracing the host range of the pycnialaecial stage. Moreover, it facilitates fungal crossing experiments
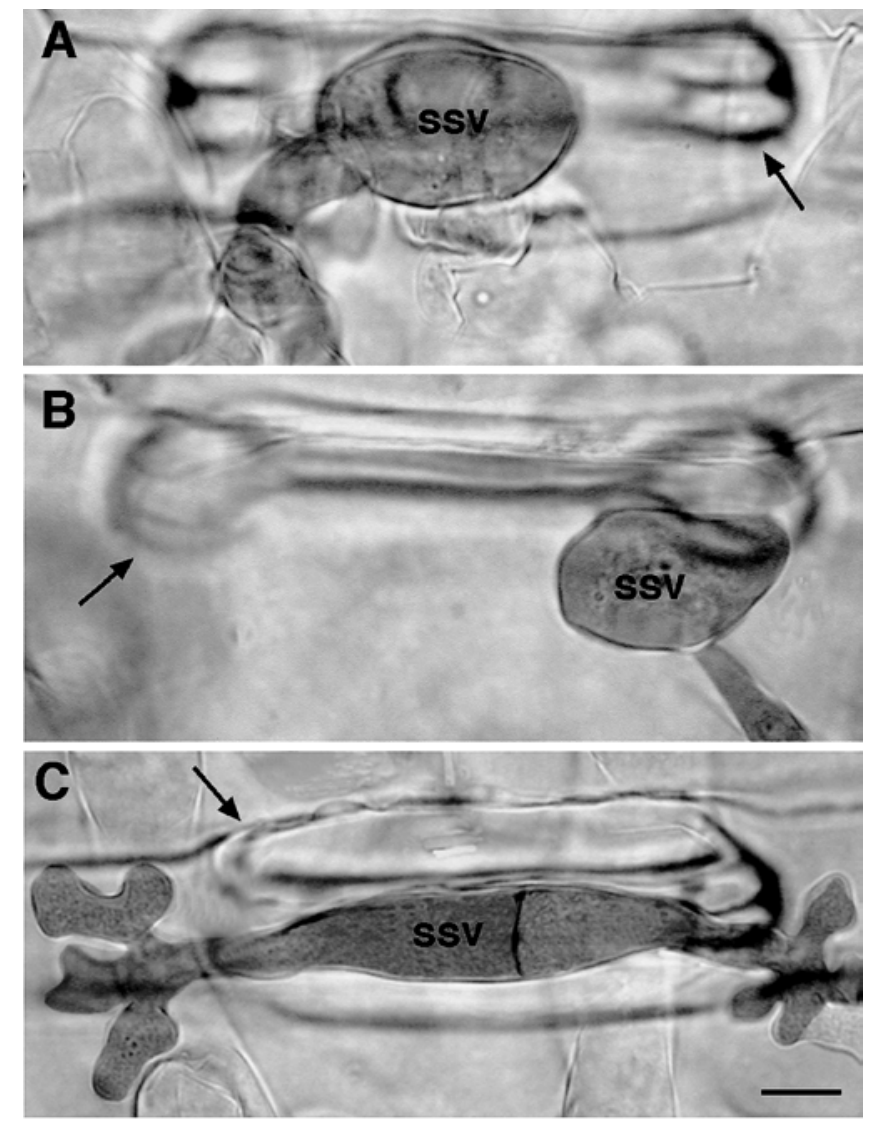

Fig. 4. Substomatal vesicles formed by the different rust types in barley cultivar L-94. A, Puccinia triticina f. sp. speltoides (speltoides type), B, $P$. triticina f. sp. tritici (wheat type), and C, P. recondita (longissima type). SSV = substomatal vesicle. Arrows indicate the invaded stomata. $\mathrm{Bar}=8 \mu \mathrm{m}$. that can provide an insight into relatedness between the rust taxa. The formation of the pycnial clusters in the greenhouse, without any danger of contamination, also facilitated the use of another independent parameter: estimates of relative amounts of nuclear DNA in the pycniospores. The estimates are made with the aid of flow cytometry of propidium iodide-stained spores. The similarity in quantities of DNA in pycniospore nuclei of the wheat and the speltoides types and the dissimilarity between this group and the longissima type of leaf rust indicated that this feature, too, can be used as a diagnostic tool.

The use of video image analysis for the measurement of spore dimensions is more accurate and faster than the classical methods of manual microscopic measurements. It also facilitates measurements of spore area. In small spores, such as rust basidiospores, in which significant differences in length or width cannot always be established accurately, comparisons of spore areas may be more reliable (Table 4; Fig. 3).

Niks' (19) technique for staining the substomatal vesicle of the urediniospore germ tube following its penetration through the stoma resulted in clear images and provided a further independent distinguishing trait.

Thus, we could establish that, in addition to being compatible with the same aecial host, the newly found speltoides type and the wheat type resemble each other in traits in which they differ from the longissima type. The main evidence for the close relationship between the two rusts is the ease with which they can be crossed to produce fertile hybrids. This is in contrast to the absence of aecia formation in the many attempts to cross either the speltoides type or the wheat type with the longissima type.

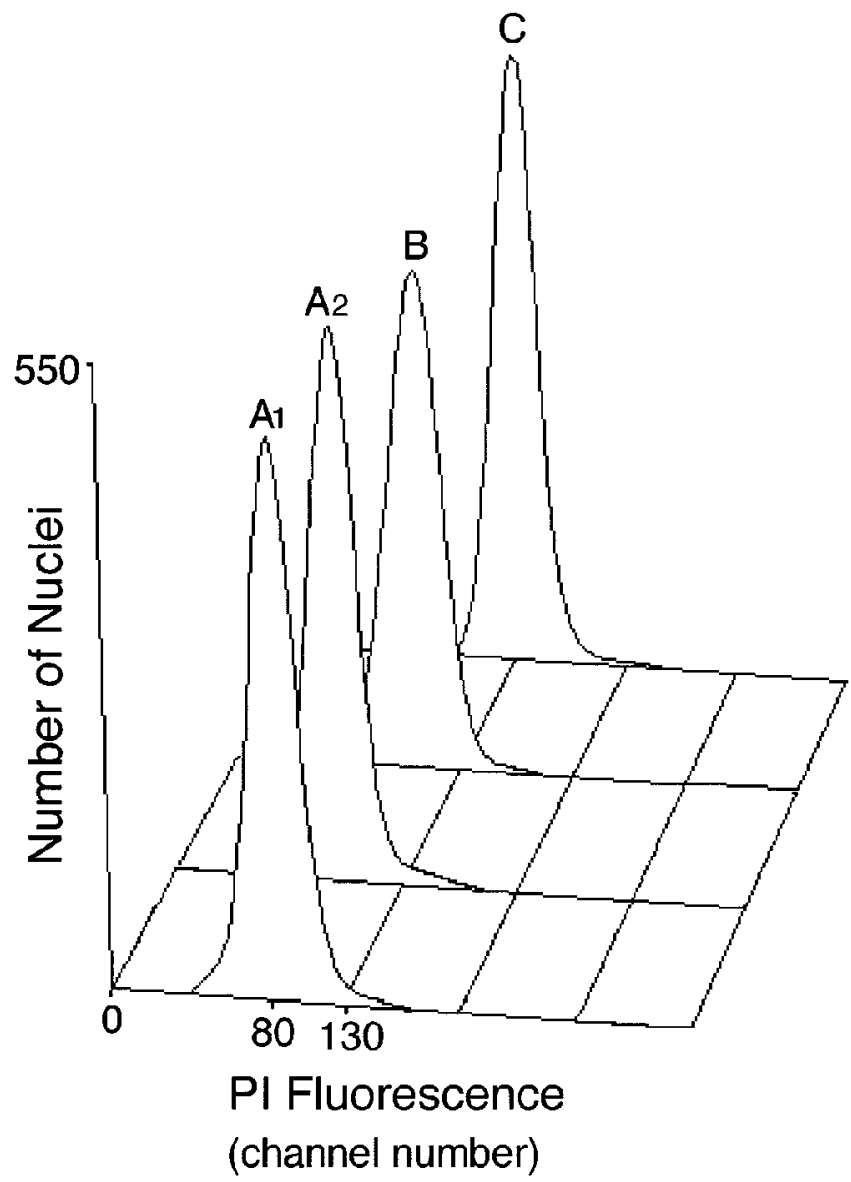

Fig. 5. Histograms showing numbers of nuclei of given fluorescence intensities obtained by flow cytometry for propidium iodide-stained pycniospores of the three rust types. $\mathbf{A}_{1}$, Puccinia triticina f. sp. speltoides (speltoides type) from Ahihud; $\mathbf{A}_{2}$, speltoides type from Qazir, B, P. triticina f. sp. tritici (wheat type), and $\mathbf{C}, P$. recondita (longissima type). 
One morphological trait, the mean number of germ pores in the urediniospore, in which the wheat type bore a closer resemblance to the longissima type than to the speltoides type, is discounted here because, in our observations, the range in pore numbers in the wheat type overlapped with that in other rust types. According to Swertz (25), a wide range in the number of germ pores in urediniospores of $P$. triticina also is reported by other authors. Traits of germ pores in the urediniospore generally are not useful as parameters for the identification of rusts, unless there is an exceptional feature in their number or arrangement, such as the equatorial arrangement of germ pores in the urediniospores of cereal stem rusts.

Taxonomic considerations. The newly found leaf rust on $A$. speltoides should be included in the $P$. triticina complex. Both the $P$. triticina and the $P$. recondita complexes contain rust fungi that are parasitic on wheat. The former, "leaf rust of wheat," has a worldwide distribution, whereas the $P$. recondita complex that alternates on boraginaceous hosts includes several rust taxa, one that attacks durum wheat only in Morocco, Portugal, and Spain $(9,20)$. Anikster et al (2) have assigned the pathogen denoted as longissima type to the $P$. recondita complex. This $P$. recondita rust is widespread in Israel and attacks different species of Aegilops (2). Two other members of this complex are $P$. recondita of rye and $P$. recondita of $A$. ovata (3).

Lacking our tools for identification, Oliveira and Samborski (20) and Wilson and Henderson (26) included taxa that, we believe, belong to different complexes into a single group. Recently, Markova and Urban (16) in their comprehensive work on P. persistens $(=P$. triticina), divided this group into 14 subspecies and varieties. One variety, $P$. persistens var. cerinthes-agropyrina, alternates on members of Boraginaceae, the family to which all aecial hosts of $P$. recondita belong. We suggest that this rust taxon should undergo further study, using the diagnostic features used in the present study.

Relevance of the speltoides type rust to studies of disease resistance. The speltoides type is of interest for an understanding of the genetics of virulence in pathogens that attack wheat cultivars and their relatives. By itself, this rust presents no danger to cultivated wheat, with which it is strictly incompatible, including wheat lines that harbor the genes $L r 28, L r 35, L r 36$, and $L r 47$ transferred from $A$. speltoides. Furthermore, the $33 \mathrm{~F}_{1}$ cultures that emerged out of the cross between wheat type and speltoides type rusts did not attack bread wheat.

Inheritance of fungal virulence genes. The reactions produced by 73 self progenies of the two rust types on two accessions of $A$. speltoides on a durum and a bread wheat (Table 3 ) resembled the reactions produced by their parents. This leads us to conclude that the parental cultures which also served as parents in the $F_{1}$ crosses carried homozygous virulence/avirulence genes. On this assumption, a simple hypothesis for the results shown on Table 3 can be proposed. The virulence reaction produced by all $\mathrm{F}_{1}$ progenies on the two A. speltoides accessions may indicate that the speltoides type rust carries a gene for virulence on $A$. speltoides that is dominant over the corresponding gene carried by the wheat type rust. The virulence reaction shown on a durum wheat cultivar to 21 progenies of speltoides type $\times$ wheat type crosses, in which the wheat type parent originated on a durum wheat, may indicate that this isolate from a durum wheat carries a dominant factor that encodes virulence to durum wheats. The reactions produced on bread wheat cv. Thatcher by progenies of the speltoides $x$ wheat type cross in which the wheat type parent originated on bread wheat may indicate dominance of the speltoides type gene for avirulence to Thatcher over the corresponding wheat type gene carried by the nectar donor in this cross.

Planned $\mathrm{F}_{2}$ progeny tests of our crosses between the speltoides and the wheat type should broaden our knowledge of the genes responsible for the differences in the telial host range of the two rust forms.
The speltoides type as a forma specialis of $\boldsymbol{P}$. triticina. The single difference between the speltoides and wheat types that emerges from this study is the distinct telial host range of each group. All 40 different bread wheat cultivars, and 70 durum wheat and $5 \mathrm{~T}$. dicoccum lines that originated in diverse parts of the world, gave 0 or 0 ; reactions when inoculated with speltoides type isolates. In contrast, these cultivars produced a 3 reaction to the wheat type isolate used in this study as well as a 3 reaction to most of 25 different isolates from different sources used in our previous studies $(2,3,13)$.

The 300 accessions of $A$. speltoides tested in the present study produced a 0 or 0 ; reaction to inoculation with the three isolates of $P$. triticina used (Tables 2 and 3 ). In many additional tests carried out over the years $(2,3,13,15,22)$, in which other isolates of $P$. triticina from wheat were used in inoculations of $A$. speltoides lines, we have found only four cases of susceptibility in accessions of A. speltoides. However, inoculating these 300 A. speltoides accessions with the speltoides type isolates gave rise to reaction type 3 on all of the accessions.

On the basis of this clear-cut difference in the host species range of the two rusts, the newly found leaf rust on A. speltoides should be considered as a forma specialis (f. sp. speltoides) of $P$. triticina.

\section{ACKNOWLEDGMENTS}

We thank the Lieberman-Okinow Endowed Chair for Disease Resistance Breeding in Cereal Crops, University of Minnesota, for research support; and A. Horovitz, K. J. Leonard, and M. Scholler for valuable comments.

\section{LITERATURE CITED}

1. Anikster, Y. 1986. Teliospore germination in some rust fungi. Phytopathology 76:1026-1030.

2. Anikster, Y., Bushnell, W. R., Eilam, T., Manisterski, J., and Roelfs, A. P. 1997. Puccinia recondita causing leaf rust on cultivated wheats, wild wheats and rye. Can. J. Bot. 75:2082-2096.

3. Anikster, Y., Long, D. L., and Manisterski, J. 1992. Response to wheat leaf rust of Aegilops spp. collected in Israel. (Abstr.) Phytopathology $82: 140$.

4. Antonov, A. I., and Marais, G. F. 1996. Identification of leaf rust resistance genes in Triticum species for transfer to common wheat. South Afr. J. Plant Soil 13:55-60.

5. Bothmer, R. von, Seberg, O., and Jacobsen, N. 1992. Genetic resources in Triticeae. Hereditas 116:141-150.

6. Cummins, G. B. 1971. The Rust Fungi of Cereals, Grasses and Bamboos. Springer-Verlag, New York.

7. Dvorak, J., and Knott, D. R. 1990. Location of a Triticum speltoides chromosome segment conferring resistance to leaf rust in Triticum aestivum. Genome 33:892-897.

8. Eilam, T., Bushnell, W. R., and Anikster, Y. 1994. Relative nuclear DNA content of rust fungi estimated by flow cytometry of propidium iodidestained pycniospores. Phytopathology 84:728-735.

9. Ezzahiri, B., Diouri, S., and Roelfs, A. P. 1992. Anchusa italica as an alternate host for wheat leaf rust in Morocco. Plant Dis. 76:1185.

10. Freitas, A. P. C. 1961. Puccinia recondita Rob. II-Survey of biotypes during the year 1958 and reaction of some wheats in the seedling stage. Agron. Lusit. 23:85-102. (In Portuguese.)

11. Jennings, D. M., Ford Lloyd, B. V., and Butler, G. M. 1989. An aniline blue squash technique for observation of urediniospores germ pores. Mycol. Res. 92:230-232.

12. Kerber, E. R., and Dyck, P. L. 1990. Transfer to hexaploid wheat of linked genes for adult-plant leaf rust and seedling stem rust resistance from an amphiploid of Aegilops speltoides $\times$ Triticum monococcum. Genome 33:530-537.

13. Korakh, T. 1995. Pathogenicity of leaf rust (Puccinia recondita) to species of the genera Triticum, Aegilops and Secale. M.S. thesis. Department of Botany, Tel-Aviv University, Tel-Aviv, Israel. (In Hebrew with English summary.)

14. Lukaszewski, A. J., Porter, D. R., Antonelli, E. F., and Dubcovsky, J. 2000. Registration of UCRBW98-1 and UCRBW98-2 wheat germplasm with leaf rust and greenbug resistance genes. Crop Sci. 40:590.

15. Manisterski, J., Segal, A., Levy, A. A., and Feldman, M. 1988. Evaluations of Israeli Aegilops and Agropyron species for resistance to wheat leaf rust. Plant Dis. 72:941-944. 
16. Markova, J., and Urban, Z. 1997. The rust fungi of grasses in Europe. 6. Puccinia persistens Plow., P. perplexans Plow., and P. elymi Westend. Acta Univ. Carol. 41:329-402.

17. McIntosh, R. A., Wellings, C. R., and Park, R. F. 1995. Wheat Rusts, an Atlas of Resistance Genes. Kluwer Academic Publishers, London.

18. Niks, R. E. 1986. Variation of mycelial morphology between species and formae speciales of rust fungi of cereals and grasses. Can. J. Bot. 64:2976-2983.

19. Niks, R. E., and Dekens, R. G. 1987. Histological studies on the infection of triticale, wheat and rye by Puccinia recondita f. sp. tritici and $P$. recondita $\mathrm{f}$. sp. recondita. Euphytica 36:275-285.

20. Oliveira, D. B., and Samborski, D. J. 1966. Aecial stage of Puccinia recondita on Ranunculaceae and Boraginaceae in Portugal. Pages 133150 in: Proc. Cereal Rusts Conf. 1964. R. C. F. Macer and M. S. Wolfe, eds. Plant Breeding Institute, Cambridge, UK.

21. Roelfs, A. P., Singh, R. P., and Saari, E. E. 1992. Rust Diseases of Wheat: Concepts and Methods of Disease Management. CIMMYT, Mexico, D.F.
22. Rothchild, H., Manisterski, J., and Anikster, Y. 1988. Reaction of Triticum dicoccoides populations and several Aegilops species to Israeli isolates of Puccinia recondita tritici. Phytoparasitica 16:77-78.

23. Samborski, D. J. 1985. Wheat leaf rust. Pages 39-52 in: The Cereal Rusts. Vol. II. A. P. Roelfs and W. R. Bushnell, eds. Academic Press, Orlando, FL

24. Schafer, F. J. 1987. Rusts, smuts and powdery mildew. Pages 542584 in: Wheat and Wheat Improvement. A Series of Monographs. Agronomy 13. E. G. Heyne, ed. American Society of Agonomy, Madison, WI.

25. Swertz, C. A. 1994. Morphology of germlings of urediniospores and its value for the identification and the classification of grass rust fungi. Stud. Mycol. No. 36. Inst. Royal Netherlands Acad. Sci. and Letters, Centraalbureau voor Schimmelcultures, Baarn and Delft, the Netherlands.

26. Wilson, M., and Henderson, D. M. 1966. British Rust Fungi. Cambridge University Press, Cambridge, UK. 